\title{
Inflação e regimes cambiais: análise de painel
}

Inflation and exchange rate regimes: a panel data analysis

\author{
Carlos de Almeida Cardoso \\ Caixa Econômica Federal \\ Flavio Vilela Vieira \\ Universidade Federal de Uberlândia
}

\begin{abstract}
The main goal of this work is to investigate inflation determinants taking into account the role of exchange rate regimes, fiscal and monetary policy elements, and also to address the relevance of the international financial crisis and the adoption (or not) of inflation target. The analysis is developed for a set of 82 economies in the period of 1990-2009. The empirical results for the three periods analyzes (1990 to 2009, 1990 to 1999 , and 2000 to 2009), focusing in understanding the relation between exchange rate regime and inflation reveals a nonconsensual pattern. The evidences also suggests the relevance of other variables for inflation, including money growth rate, government debt, changes in the real effective exchange rate, real interest rate and lagged inflation. An additional evidence indicates that inflation target countries are associated to lower inflation, but this result is restricted to the period of 1990 to 1999.
\end{abstract}

\section{Keywords}

inflation; exchange rate regime; Panel Data analysis.

JEL Codes C33; E31; F31.

\section{Resumo}

Este trabalho tem como objetivo principal investigar os determinantes da inflação, considerando o papel dos regimes cambiais, elementos da política fiscal e monetária, além da investigação do papel das crises financeiras e da adoção ou não do regime de metas de inflação. A análise é desenvolvida para um conjunto de 82 economias no periodo de 1990 a 2009. Os resultados empíricos dos três periodos avaliados (1990 a 2009, 1990 a 1999 e 2000 a 2009), focando no entendimento da relação entre regime cambial e inflação, revela um caráter dúbio ou não consensual. As evidências indicam ainda a importância de outras variáveis para o comportamento da inflação, como a taxa de crescimento da oferta monetária, a dívida do governo, a variação da taxa de câmbio real efetiva, a taxa de juros real, além da relevância da inflação defasada. Uma evidência adicional é de que os países que adotaram o regime de metas de inflação estão associados a taxas inflacionárias mais baixas, resultado esse restrito ao periodo de 1990 a 1999.

\section{Palavras-chave}

inflação; regimes cambiais; análise de dados em painel.

Códigos JEL C33; E31; F31. 


\section{Introdução}

O trabalho tem como objetivo principal investigar os determinantes da inflação, considerando o papel dos regimes cambiais, elementos da política fiscal e monetária, além da investigação do papel das crises financeiras e da adoção ou não do regime de metas de inflação. A análise é desenvolvida para um conjunto de 82 economias no período de 1990 a 2009.

O estudo utiliza a análise de dados em painel com a metodologia System GMM, em distintos períodos, de 1990 a 2009, de 1990 a 1999 e de 2000 a 2009. A análise empírica investiga ainda o papel dos diferentes tipos de crise (bancária, cambial e monetária, reversão brusca nos fluxos de capitais e de endividamento) nos modelos e se a adoção do regime de metas de inflação tem impacto sobre a inflação.

O presente trabalho pretende contribuir para os estudos empíricos de modelos de inflação, utilizando a metodologia System GMM, tendência recente da literatura, além de usar amostras mais amplas e/ou dados mais recentes comparados aos estudos avaliados. A contribuição empírica do trabalho está associada não apenas à utilização da metodologia em referência, mas também em lidar com a proliferação de instrumentos, o que é frequente ocorrer quando da utilização da metodologia System GMM, e com a especificação de modelos que permitam investigar o papel dos diferentes tipos de crise, de regimes cambiais e das metas de inflação. A maioria dos modelos de inflação em geral não trata essas três dimensões (crises, regimes cambiais e metas de inflação) de forma conjunta em um único trabalho, e essa é uma das contribuições empíricas a ser destacada.

A primeira metade da década de 1990 é um período em que o debate sobre a escolha dos diferentes regimes cambiais evidenciava uma defesa mais ampla a favor da adoção dos regimes cambiais intermediários nas economias em desenvolvimento e emergentes, em vista dos diversos objetivos macroeconômicos existentes, tais como credibilidade e flexibilidade, crescimento econômico e inflação ou o isolamento a choques econômicos reais e monetários. No entanto, em vista das crises financeiras vivenciadas por importantes países desse grupo de economias em meados dos anos 1990 e da visão de que tais regimes seriam mais propensos a crises, argumentos a favor de escolhas "bipolares", também chamadas de "soluções de 
canto", foram se tornando mais robustos. ${ }^{1}$

Já o final da década de 1990 revela a existência de diferentes graus de mobilidade de capital entre as economias em desenvolvimento e emergentes e do trade-off existente entre os objetivos de estabilidade da taxa de câmbio, independência monetária e integração nos mercados financeiros, o que poderia ser resolvido com soluções mais intermediárias, indicando preferência por regimes cambiais intermediários. Além disso, a abordagem do fear of floating reforça tal debate, já que as economias emergentes que se declaravam com regimes flexíveis, na prática, conduziam seus regimes por meio de intervenções com vistas a maior estabilidade cambial e evitar repasses de variações cambiais para os preços (pass through).

Nesse contexto, um aspecto considerado no debate refere-se aos impactos dos diferentes regimes cambiais sobre a inflação. A literatura teórica e empírica que trata dos efeitos dos diferentes regimes de câmbio sobre a inflação, de maneira geral, mostra que existe forte relação entre taxas de câmbio fixas / rígidas e baixa inflação, resultado de um efeito disciplina e de um efeito credibilidade. Há uma associação de baixa inflação com taxas de câmbio fixas, uma vez que as economias que convivem com menor inflação têm maior competência para manter um regime cambial peg, mas há também evidência de causalidade de que os países que escolhem esse tipo de regime cambial conseguem reduzir sua inflação.

Os anos mais recentes revelam, na prática, a adoção de significativas medidas de forma a afetar a trajetória da taxa de câmbio nas mais diversas economias. Tal cenário se torna bastante comum em função da ocorrência de significativas e duradouras apreciações da taxa de câmbio real, que devem ser administradas caso se deseje bom desempenho das contas externas, e em função de recorrentes disputas comerciais que se acirraram com a crise financeira internacional desde 2008.

A estrutura deste artigo está dividida em três seções. A primeira seção apresenta breve introdução, e a segunda seção, uma revisão da literatura teórica e empírica sobre a relação entre regimes cambiais, inflação e metas de inflação. A terceira seção é dedicada aos aspectos metodológicos e à sistematização dos resultados econométricos, além de apresentar as considerações finais do trabalho.

1 Os anos 1990 foram marcados por recorrentes opções de vários países pela adoção de uma âncora cambial (regime de câmbio rígido ou fixo) enquanto estratégia de combate inflacionário. 


\section{Revisão da literatura teórica e empírica: inflação, regimes cambiais, metas de inflação e crises financei- ras}

A escolha entre diferentes regimes cambiais, dos mais rígidos aos mais flexíveis, envolve, essencialmente, um trade-off entre redução na volatilidade da taxa de câmbio e perda de autonomia na condução da política monetária. A literatura teórica abrange ampla variedade de estudos que abordam, principalmente, os custos e benefícios envolvidos nas diferentes escolhas, os quais podem ser contemplados, segundo Ghosh et al. (2002), em três linhas principais: i) nas propriedades dos regimes cambiais; ii) quanto à integração econômica; e iii) na política de credibilidade. Vale destacar, entretanto, que argumentos não econômicos também influenciam de forma significativa essa escolha, situação em que prevalecem aspectos políticos subjacentes.

Em relação à teoria sobre as propriedades dos regimes cambiais, essa originou-se com base nos artigos seminais de Fleming (1962) e Mundell (1963), os quais apontam que, essencialmente, existem diferentes implicações macroeconômicas na conduta da política de estabilização para os regimes fixos e os regimes flexíveis sob diferentes condições de mobilidade de capitais.

O modelo básico de Mundell-Fleming evidenciou que os regimes cambiais podem alterar a efetividade da política monetária e fiscal, sugerindo que as condições de regime de câmbio fixo, mobilidade de capitais e política monetária independente formam um "policy trilemma", o chamado Princípio da Tríade Impossível. Nesse caso, sob condições de alta mobilidade de capitais internacionais, o regime fixo implica renúncia da autonomia monetária.

Consequentemente, esse Princípio, como já dito, acarretaria que os países devessem abrir mão de um dos objetivos, de estabilidade da taxa de câmbio, de independência monetária ou de integração nos mercados financeiros. Entretanto, a teoria não pressupõe que os governos escolham apenas soluções de canto, combinando duas dessas políticas em detrimento de uma terceira. ${ }^{2}$

Ainda considerando as propriedades dos regimes cambiais, a incidência relativa de choques nominais e choques reais na economia se torna outro aspecto importante na escolha do regime de câmbio, uma vez que, sob

2 A discussão sobre soluções de canto (bipolaridade) é sistematizada por Fischer (2001). 
alta mobilidade de capitais, o regime flexível é considerado como mais adequando quando se considera a possibilidade de isolar o nível de produto doméstico aos choques reais externos já que as alterações na taxa de câmbio podem mitigar tais efeitos, e de outro lado o regime de câmbio mais rígido é considerado mais adequado quando o objetivo é minimizar os impactos de choques nominais. ${ }^{3}$

A teoria de área monetária ótima, também desenvolvida por Mundell (1961), fornece boa representação para o entendimento da escolha de regimes cambiais, envolvendo no caso, a adoção de um regime de moeda única que implica a perda da taxa de câmbio nominal como mecanismo de ajuste. Mecanismos de ajuste alternativos entre os países-membros, porém podem compensar a renúncia ao câmbio como variável de ajuste, tais como flexibilidade de emprego e preços, mobilidade dos fatores e sistemas de transferências fiscais, e os ganhos se elevam na medida da extensão de integração de comércio entre os países.

Desta forma, se, por um lado, os benefícios potenciais em dividir uma moeda comum aumentam com a integração no comércio e investimento entre os países, por outro os custos potenciais também se elevam com as diferenças nos choques macroeconômicos ou com a ausência desses mecanismos de absorção de choques entre os países-membros, a exemplo das transferências fiscais. Para o caso de estabelecimento de um regime peg entre dois países, aspectos similares oriundos da teoria de área monetária ótima se aplicam, sendo um ponto central a condição de que os países estejam relativamente sujeitos a choques no produto de forma similar e altamente correlacionada.

Em relação à política de credibilidade, cabe destacar, inicialmente, que essa linha teórica foi motivada pelas experiências de alta inflação nas décadas de 1960 e 1970, dando ênfase aos aspectos de credibilidade dos regimes monetários e dos regimes cambiais. Os regimes de câmbio fixos são vistos como potencial âncora nominal para a inflação, uma vez que exercem influência sobre as expectativas dos agentes e ajudam os bancos centrais a atingir seu objetivo de inflação, conforme a fundamentação teórica de Barro e Gordon (1983) por meio de um modelo para uma economia fechada. ${ }^{4}$

3 Ver Edwards e Levy-Yeyati (2005) para uma discussão detalhada sobre o papel das taxas de câmbio flexível em absorver choques externos.

4 Os detalhes sobre o modelo podem ser verificados no trabalho de Barro e Gordon (1983). 
Na perspectiva de uma economia aberta, ao fixar a taxa de câmbio nominal com o objetivo de se obter inflação baixa, o país cria um dispositivo de pré-compromisso. O peg não elimina o incentivo de se gerar surpresas inflacionárias, mas impõe uma restrição na capacidade do Banco Central em agir dado o incentivo existente. Sendo endógena a decisão de se preservar o regime fixo, o pré-compromisso se estende até o ponto em que os custos de abandonar o regime, sejam políticos, sejam de outra natureza, superam os benefícios de se gerar surpresa na inflação. Desta forma, maiores custos de saída do regime, como exemplo, a adoção em lei de um peg mais rígido, pode aumentar a credibilidade do Banco Central, tornando mais fácil para a autoridade monetária atingir e manter uma inflação baixa.

Segundo Klein e Shambaugh (2010), a análise da credibilidade da política monetária proporciona um canal adicional em que a escolha do regime da taxa de câmbio pode afetar o comportamento da inflação. $O$ argumento subjacente é que a percepção das preferências de política do Banco Central afeta o desempenho da inflação, ou seja, ocorre um efeito de credibilidade. ${ }^{5}$

Friedman (1968) define teoricamente a inflação como um fenômeno monetário, e, por sua vez, Klein e Shambaugh (2010) argumentam que os regimes de câmbio são construções monetárias, resultado do policy trilemma, pois, como visto, a política monetária se subordina à taxa de câmbio (fixa/rígida) na presença de mobilidade de capitais.

Ghosh et al. (1997a) argumentam que existe forte relação entre taxas de câmbio fixas e baixa inflação, resultado de um efeito disciplina, uma vez que os custos políticos de se abandonar o peg leva a políticas mais restritivas, e de um efeito credibilidade, já que maior confiança leva a maior disposição em se manter moeda doméstica em vez de bens ou moedas estrangeiras. Há uma associação de baixa inflação com taxas de câmbio fixas porque os países que convivem com baixa inflação estão mais aptos a manter um peg, mas há também evidência de causalidade de que os países que escolhem esse tipo de regime conseguem baixar sua inflação. Ou seja, o regime peg pode baixar a inflação pela indução de maior disciplina na política e proporcionar maior credibilidade à moeda.

Do ponto de vista das evidências empíricas, tanto Ghosh et al. (1997a) quanto Klein e Shambaugh (2010) mostram resultados sugerindo que um 5 Os trabalhos teóricos seminais sobre o tema são Kydland e Prescott (1977), Calvo (1978), Barro e Gordon (1983) e Rogoff (1985). 
regime peg afeta a inflação através de ambos os efeitos, pela disciplina e pela credibilidade.

Alguns estudos empíricos importantes que avaliam o impacto dos regimes cambiais sobre a inflação e que utilizam a metodologia System GMM, são trabalhos como os de Stotsky et al. (2012) e De Grauwe e Schnabl (2008), os quais também encontram resultados evidenciando a relação significativa entre a taxa de câmbio e a inflação.

Stotsky et al. (2012) investigam a relação entre o regime cambial e o desempenho macroeconômico na África Oriental. Nessa região, em especial, o controle da inflação se torna um desafio muito importante, já que os países se movem em direção a regimes cambiais mais flexíveis. A metodologia de painel dinâmico System GMM é utilizada para lidar com a endogeneidade potencial de variáveis explicativas. $O$ período avaliado é de 1990 a 2010, em uma amostra de sete países da região em estudo. Os resultados apresentam relação significativa entre os movimentos da taxa de câmbio e a inflação, não havendo evidência para um pass through completo. Apontam também que a inflação defasada, o crescimento amplo da moeda e o posicionamento fiscal são determinantes-chave da inflação, sugerindo papéis complementares entre políticas fiscal e monetária, o que pode conter a inflação, garantindo que uma desvalorização nominal leve a uma desvalorização real. Os autores distinguem na análise os regimes de taxa de câmbio De Jure e De Facto e, como resultados mais relevantes, indicam que os regimes baseados na classificação $D e$ Jure não parecem ser importantes na determinação da inflação, ao passo que os regimes de facto exercem sobre essa um efeito negativo estatisticamente significativo. ${ }^{6}$

De Grauwe e Schnabl (2008) analisam os impactos do regime cambial na inflação (e crescimento econômico) em países da Europa Central e Sudeste, a maioria, economias em transição. Segundo os autores, no início da década de 1990, a maior parte dos países da Europa Central e Sudeste

6 Vários trabalhos detalham os diversos critérios de classificação de regimes cambiais, a exemplo de Klein e Shambaugh (2010). Reinhart e Rogoff (2004) elaboraram um critério de classificação de regimes, denominado como classificação "natural", que utiliza as taxas de câmbio do mercado paralelo para os países que possuíam um mercado de moeda dual. Os autores argumentam haver forte evidência no pós-Segunda Guerra, do uso frequente de taxas paralelas ou duais como forma de flutuação clandestina em tempos de pegs oficiais, e assim, vêm a taxa paralela como a melhor demonstração da verdadeira postura dos governos. São desenvolvidas duas versões, a versão "fine grid" do critério de classificação, que possui quinze categorias, e a versão "coarse grid", que as consolida em apenas seis categorias. 
haviam fixado suas moedas ao dólar ou a cestas de moedas compostas de dólar e moedas europeias. Entretanto, em meados dos anos 2000, as estratégias de taxas de câmbio gradualmente se redirecionaram para o euro, tornando-o âncora monetária regional e criando maior expectativa para a entrada de novos membros na União Monetária Europeia, que buscavam a estabilidade cambial, decisão que iria depender dos custos e dos benefícios percebidos por essas economias. Os autores utilizam um painel dinâmico para 18 países da região, estimando um modelo pelo método System GMM no período de 1994 a 2004. Os resultados apontam que a estabilidade da taxa de câmbio na União Europeia contribui de forma significativa para reduzir a inflação (e impactar positivamente sobre o crescimento); entretanto, essa relação desaparece em uma análise sub amostral, quando se removem outliers da amostra e também se divide o período completo em períodos de elevada inflação e de baixa inflação (o que não ocorre com o crescimento, que continua se mantendo robusto).

Ainda na linha de estudos empíricos que tratam da relação entre regimes cambiais e inflação, porém, utilizando outras diferentes metodologias econométricas, podem ser sumarizados, no quadro seguinte, alguns dos trabalhos mais relevantes da literatura na referida abordagem. Os resultados, de maneira geral, confirmam que existe forte relação entre taxas de câmbio fixas / rígidas e baixa inflação, ou seja, mostram que há efeitos negativos significativos dos regimes pegs sobre a inflação.

Além disso, uma distinta linha de estudos empíricos sobre os efeitos dos regimes de câmbio sobre a inflação toma como referência episódios nos quais a taxa de câmbio desempenhou papel central, de âncora nominal, em um processo desinflacionário da economia, a exemplo de Végh (1992), que, especificamente, analisou o papel de metas de taxa de câmbio para reverter casos de hiperinflação. ${ }^{7}$

No tocante à relação entre regimes cambiais e regime de metas de inflação, Stone et al. (2009) desenvolvem um estudo robusto sobre o papel da taxa de câmbio para as economias emergentes que adotaram o regime de metas de inflação comparativamente às economias avançadas que também seguiram o regime monetário. A referência são estudos de casos e documentação detalhada elaborados no FMI quanto às práticas da taxa de câmbio em diversos países. Os autores elaboram simulações por meio 7 Calvo e Végh (1999) apresentam um dos estudos pioneiros em analisar a relação entre regimes cambiais e inflação. 
Quadro 1 Resultados da literatura empírica sobre impactos dos regimes cambiais na inflação

\begin{tabular}{|c|c|c|c|c|}
\hline Autores & $\begin{array}{l}\text { Dados e } \\
\text { Amostra }\end{array}$ & $\begin{array}{l}\text { Classificação do } \\
\text { Regime Cambial }\end{array}$ & $\begin{array}{l}\text { Método de } \\
\text { Estimação }\end{array}$ & Resultados \\
\hline $\begin{array}{l}\text { Ghosh } \\
\text { et al. } \\
\text { (1997b) }\end{array}$ & $\begin{array}{l}1960-1990 \\
140 \text { países }\end{array}$ & $\begin{array}{l}\text { Combinação das } \\
\text { classificações De } \\
\text { Jure e De Facto. } \\
\text { Sistema tripartite } \\
\text { (pegs, interme- } \\
\text { diários e floats) }\end{array}$ & $\begin{array}{l}\text { Mínimos quadra- } \\
\text { dos ordinários } \\
\text { (MQO). }\end{array}$ & $\begin{array}{l}\text { Comparado com o regime float, } \\
\text { o regime peg afeta negativamente } \\
\text { a inflação através do papel de } \\
\text { disciplina e credibilidade, enquanto } \\
\text { o intermediário afeta apenas pela } \\
\text { disciplina direta por meio da políti- } \\
\text { ca monetária. }\end{array}$ \\
\hline $\begin{array}{l}\text { Ghosh et } \\
\text { al. (2002) }\end{array}$ & $\begin{array}{l}\text { 1970-1999 } \\
147 \text { países }\end{array}$ & $\begin{array}{l}\text { Classificação De } \\
\text { Jure e classifica- } \\
\text { ção "consenso". } \\
\text { que é interseção } \\
\text { de De Jure e De } \\
\text { Facto própria. } \\
\text { Sistema tripartite } \\
\text { (pegs, interme- } \\
\text { diários e floats) }\end{array}$ & $\begin{array}{l}\text { Mínimos quadra- } \\
\text { dos ordinários } \\
\text { (MQO). }\end{array}$ & $\begin{array}{l}\text { O resultado de } 1997 b \text { de que o regi- } \\
\text { me peg baixa a inflação e o regime } \\
\text { intermediário não, na análise de } \\
\text { subamostras em 2002, se mantém } \\
\text { apenas para economias de renda } \\
\text { mais elevada. Além disso, esses } \\
\text { regimes estão associados com me- } \\
\text { nor inflação para países de renda } \\
\text { média mais baixa, ao passo que não } \\
\text { há efeito significativo desses para } \\
\text { países de renda mais elevada. }\end{array}$ \\
\hline $\begin{array}{l}\text { Levy- } \\
\text {-Yeyati e } \\
\text { Sturze- } \\
\text { negger } \\
\text { (2001) }\end{array}$ & $\begin{array}{l}\text { 1974-1999 } \\
154 \text { países }\end{array}$ & $\begin{array}{l}\text { De Facto. Sistema } \\
\text { tripartite (pegs, } \\
\text { intermediários e } \\
\text { floats) }\end{array}$ & $\begin{array}{l}\text { Minimos qua- } \\
\text { drados em dois } \\
\text { estágios MQ2E }\end{array}$ & $\begin{array}{l}\text { Há um impacto do peg de forma } \\
\text { significativa sobre a inflação. Como } \\
\text { em Ghosh et al. (2002), Há um } \\
\text { impacto do peg na inflação para } \\
\text { países não industrializados e de } \\
\text { baixa volatilidade, mas não para } \\
\text { países industrializados. Além disso, } \\
\text { os pegs mais longos contribuem } \\
\text { para baixar a inflação nos países } \\
\text { não industrializados. }\end{array}$ \\
\hline $\begin{array}{l}\text { Husain et } \\
\text { al. (2005) }\end{array}$ & $\begin{array}{l}\text { 1970-1999 } \\
158 \text { países }\end{array}$ & De Facto & $\begin{array}{l}\text { Painel agrupado } \\
\text { e modelos de } \\
\text { efeitos fixos }\end{array}$ & $\begin{array}{l}\text { Efeito negativo significativo do } \\
\text { peg comparativamente ao freely } \\
\text { floating apenas para economias } \\
\text { emergentes e em desenvolvimento. }\end{array}$ \\
\hline $\begin{array}{l}\text { Alfaro } \\
(2005)\end{array}$ & $\begin{array}{l}1973-1998 \\
130 \text { países }\end{array}$ & $\begin{array}{l}\text { De Jure (FMI) e } \\
\text { De Facto (Rei- } \\
\text { nhart; Rogoff, } \\
\text { 2004). }\end{array}$ & $\begin{array}{l}\text { Análise de Painel } \\
\text { (Efeitos fixos) }\end{array}$ & $\begin{array}{l}\text { Há redução estatisticamente signi- } \\
\text { ficativa na inflação para países com } \\
\text { pegs em relação aos países floaters. }\end{array}$ \\
\hline $\begin{array}{l}\text { Bleaney e } \\
\text { Francisco } \\
(2007)\end{array}$ & $\begin{array}{l}\text { 1984-2001 } \\
91 \text { países }\end{array}$ & De Facto & $\begin{array}{l}\text { Análise de Painel } \\
\text { (efeitos fixos) }\end{array}$ & $\begin{array}{l}\text { Efeito negativo significativo dos } \\
\text { regimes cambiais pegs sobre a } \\
\text { inflação. }\end{array}$ \\
\hline
\end{tabular}

Fonte: Elaboração dos autores. 
de um modelo adaptado para países de economia aberta e com regime de metas de inflação. ${ }^{8}$

Stone et al. (2009) indicam para um papel mais relevante da taxa de câmbio na política monetária das economias emergentes com metas de inflação em relação às economias avançadas com o mesmo tipo de regime. Uma característica importante do grupo de economias emergentes é que essas têm arranjos de câmbio menos flexíveis e intervêm de forma mais frequente e menos transparente no mercado de câmbio. Por outro lado, quase todas as economias avançadas com o regime monetário têm flutuação independente, intervindo com muito pouca frequência no mercado de câmbio. Além disso, as economias emergentes têm exibido maior volatilidade no câmbio comparada com as economias avançadas.

Outro aspecto relevante bastante comum às economias emergentes refere-se ao fato de que esses países frequentemente respondem aos movimentos da taxa de câmbio utilizando mudanças nas taxas de juros, por meio das funções de reação dos bancos centrais, como pode ser visto pela literatura empírica apresentada na sequência.

O papel mais destacado da taxa de câmbio nas economias emergentes reflete, assim, sua maior vulnerabilidade aos choques sobre o câmbio e o fato de essas economias terem mercados financeiros menos desenvolvidos. O elevado pass through para a inflação e o impacto no produto advindo dos movimentos na taxa de câmbio, o efeito balancete em vista dos descasamentos de moeda e a baixa credibilidade na política reforçam a importância do papel da taxa de câmbio nessas economias. O alerta é que o maior foco na taxa de câmbio pode causar alguma confusão quanto ao compromisso dos bancos centrais em relação às metas de inflação, complicando também a implementação de política.

Biondi e Toneto Júnior (2008), por outro lado, desenvolvem um trabalho com o método System GMM avaliando os impactos do regime de metas de inflação, o qual pressupõe um regime cambial flutuante ou intermediário sobre o desempenho econômico dos países e demonstram que o regime de metas traz impactos significativos para as taxas de inflação (e crescimento real do produto) dos países, especialmente para o grupo de países em desenvolvimento. A amostra de dados da análise econométrica se compõe de 51 países para o período de 1995 a 2004, tendo como grupo de tratamento

8 Os detalhes sobre o modelo podem ser verificados no trabalho de Stone et al. (2009). 
o grupo de países que adotam metas de inflação e como grupo de controle o grupo dos países que não adotam o regime, sendo 24 deles países em desenvolvimento. Os resultados empíricos indicam que, dentre os países desenvolvidos, o grupo dos que adotam o sistema de metas de inflação mostra taxas de inflação e de crescimento do produto um pouco maiores relativamente aos países desenvolvidos que não adotam o regime monetário. Apesar desse pequeno efeito, isso não se mostra muito relevante, uma vez que historicamente os países desenvolvidos já apresentam taxas de inflação baixas e estáveis. Para o caso dos países em desenvolvimento, porém, a adoção do regime de metas se mostra eficaz em reduzir as taxas médias de inflação dos países; no entanto, isso parece provocar efeitos negativos sobre o crescimento do produto real da economia. Assim, países em desenvolvimento enfrentam maiores custos pela manutenção do regime de metas, já que tendem a enfrentar maiores dificuldades na construção da credibilidade, e, para elevar sua reputação, as autoridades monetárias tendem a seguir políticas monetárias restritivas e a operar com maior rigidez. No entanto, conclui-se que o regime de metas se mostra como boa alternativa para os países em desenvolvimento com o objetivo de ancorar as expectativas dos agentes e de controlar a inflação em patamares baixos.

Um resultado comum verificado em Edwards (2006), Calvo e Reinhart (2002) e Mohanty e Klau (2004) é que a maioria dos países de economia emergente que adotaram o regime de metas inflação tende a limitar os movimentos da taxa de câmbio por meio da condução da política monetária, ao custo de maior variabilidade nas taxas de juros.

Edwards (2006) elaborou um estudo empírico sobre os países que adotaram o regime de metas de inflação e argumenta que as economias emergentes passaram a enfrentar dificuldades com a flutuação cambial e com seus efeitos sobre a inflação e o produto da economia. $O$ autor encontra evidências de que esses países apuraram queda no grau de passthrough das taxas de câmbio para a inflação com a adoção do regime de metas, sem mostrar, no entanto, mudanças no grau de eficiência do câmbio nominal como absorvedor de choques. Além disso, os países com histórico de inflação instável e elevada que adotaram o referido regime também tendem a considerar explicitamente os movimentos da taxa de câmbio nominal na condução da política monetária.

Calvo e Reinhart (2002) já haviam demonstrado empiricamente que as economias emergentes limitavam as flutuações cambiais em busca de 
maior estabilidade do câmbio, ao custo de maior volatilidade nas taxas de juros, caracterizando o fear of floating.

Mohanty e Klau (2004), testando as funções de reação adotadas pelos bancos centrais de um grupo de economias emergentes, demonstraram que, na maioria desses países, a taxa de juros responde fortemente à variação da taxa real de câmbio, reforçando a importância da taxa de câmbio como fonte de choques nessas economias e sustentando a hipótese do fear of floating. ${ }^{9}$

\section{Estimação econométrica e resultados}

A seção 3 do trabalho encontra-se dividida em quatro subseções, sendo a primeira dedicada à metodologia econométrica utilizada (System GMM), à medida que as outras três subseções sistematizam os resultados para o período total (1990 a 2009), subperíodo de 1990 a 1999 e para o subperíodo de 2000 a 2009, para então se apresentar as considerações finais do trabalho.

\subsection{Metodologia econométrica}

A metodologia econométrica do trabalho concentra-se na análise de um modelo de dados de painel dinâmico, e o método de estimação é o método dos momentos generalizados (GMM), tendo como referência os trabalhos de Arellano e Bond (1991), Arellano e Bover (1995) e Blundell e Bond (1998). ${ }^{10}$

O uso desse modelo se justifica em vista de que muitas relações econômicas são relações dinâmicas, significando que séries econômicas se relacionam umas com as outras e também com seus valores passados; nesse sentido, os modelos de painel dinâmico consideram a variável dependente defasada como uma variável endógena. Diferentemente dos modelos de painel estático, em que ocorre viés nos coeficientes estimados quando se incluem variáveis dependentes defasadas como regressores, as estimativas

9 Taylor (2001), por outro lado, argumenta que os modelos teóricos mostram que as regras monetárias que reagem de forma direta à taxa de câmbio, além da taxa de inflação e produto, não contribuem para a estabilização da inflação e do produto real, e, algumas vezes, esses modelos obtêm resultados piores do que as regras monetárias que não reagem diretamente à variável taxa de câmbio.

10 O software utilizado para as estimações econométricas é o Stata 11. 
com modelos de painel dinâmico por meio do método GMM podem fornecer estimadores não viesados.

Ou seja, essa metodologia contempla, além dos efeitos fixos individuais, a dimensão de séries temporais dos dados e a possibilidade de inclusão da variável dependente defasada entre as variáveis explicativas, também permitindo que todas as variáveis explicativas sejam endógenas no modelo.

Assim, na equação de inflação abaixo, o que caracteriza a relação econômica dinâmica é a presença da variável dependente defasada como uma das variáveis explicativas, conforme se observa:

$$
I N F_{i t}=\lambda I N F_{i, t-1}+X_{i t}^{\prime} \beta+u_{i t}, \text { com } \mathrm{i}=1, \ldots, \mathrm{N} \text { e } \mathrm{t}=1, \ldots, \mathrm{T}
$$

Sendo que INF é a taxa anual de inflação; $X_{i t}^{\prime}$ é o vetor de variáveis explicativas, que podem ser estritamente exógenas, endógenas ou predeterminadas; e $u_{i t}$ é o componente de erro. ${ }^{11}$

O uso de instrumentos é necessário para lidar com a possível endogeneidade das variáveis explicativas e a correlação entre o termo de erro e a variável dependente defasada. Sob as hipóteses que o termo de erro não é serialmente correlacionado e as variáveis explicativas são fracamente exógenas, valores defasados das variáveis explicativas podem ser usados como instrumentos.

Arellano e Bond (1991) desenvolveram o chamado Difference GMM, porém, com os regressores na equação sendo persistentes; então, os níveis defasados se tornam instrumentos fracos, gerando problemas ao se utilizar tal estimador. Os instrumentos fracos assintoticamente implicam aumento da variância dos coeficientes e, no caso de amostras pequenas, podem implicar coeficientes viesados.

Desta forma, para reduzir o viés potencial e os problemas de inconsistência do estimador Difference GMM, Arellano e Bover (1995) e Blundell e Bond (1998) desenvolveram um sistema de regressões em diferenças e níveis, adicionando ao Difference GMM a equação original em nível, aumentando a eficiência em vista da presença de mais instrumentos. Tem-se, então, um sistema com duas equações, conhecido como System GMM, em que, na equação em diferença, as variáveis em diferença são instrumentalizadas com suas defasagens disponíveis em nível, ao passo que, na equação 11 As estimações System GMM incluem, além das variáveis explicativas convencionais, dummies temporais. 
em nível, as variáveis em nível são instrumentalizadas com defasagens adequadas das próprias primeiras diferenças, sendo importante destacar que as diferenças das variáveis instrumentalizadas e os efeitos fixos individuais são não correlacionados.

Para testar a consistência do estimador System GMM, são considerados dois testes de especificação baseados em Arellano e Bond (1991), Arellano e Bover (1995) e Blundell e Bond (1998). O primeiro, teste de Hansen, é um teste de restrições sobreidentificadoras, em que a hipótese nula conjunta é que os instrumentos são válidos, ou seja, são não correlacionados com o termo de erro, e os instrumentos excluídos são corretamente excluídos da equação estimada. O segundo, teste Arellano-Bond, testa a hipótese de ausência de correlação serial, e pode ocorrer autocorrelação de primeira ordem, porém, o mesmo não acontece quando se analisa a autocorrelação de segunda ordem.

Levando em consideração que a estimação por System GMM pode resultar no uso de muitos instrumentos, Roodman (2009b) discute os sintomas da proliferação de instrumentos mostrando que, à medida que a dimensão temporal aumenta, o número de instrumentos pode se tornar grande em comparação ao tamanho da amostra e invalidar alguns resultados assintóticos e testes de especificação. Um dos argumentos é que muitos instrumentos podem sobreajustar as variáveis endógenas e falhar ao expurgar seus componentes endógenos, o que resulta em viés nos coeficientes estimados, e o outro argumento é que os testes Hansen e Difference-in-Hansen podem ser fracos quando se utiliza o System GMM na presença de sobreidentificação.

Desta forma, um dos procedimentos para reduzir o número de instrumentos é utilizar apenas algumas defasagens em vez de todas as defasagens disponíveis. Conforme Roodman (2009a), outro procedimento é a combinação de instrumentos através da adição em conjuntos menores, utilizando-se o comando Collapse no Stata.

Ainda com relação à modelagem, com o intuito de criar variáveis dummies para crises cambiais e monetárias, crises bancárias sistêmicas e crises de dívida, foram utilizados os critérios e a base de dados de Laeven e Valencia (2008), ao passo que, para as dummies de crises de sudden stops, ou seja, de interrupção súbita de fluxo de capitais, foram utilizadas as informações de Calvo et al. (2008). ${ }^{12}$

12 Laeven e Valencia (2008) consideram como uma crise cambial e monetária (crise de moeda) as depreciações nominais da moeda de magnitude de pelo menos $30 \%$ e que sig- 


\subsection{Resultados empíricos (1990 a 2009)}

Os resultados das estimações econométricas por System GMM dos modelos de inflação no período de 1990 a 2009 para uma amostra de 82 países são apresentados na Tabela 1, para que se possa avaliar sinal, significância estatística, magnitude dos diferentes coeficientes estimados e os testes realizados (autocorrelação de segunda ordem e de validade dos instrumentos) ${ }^{13}$ A estimação econométrica foi realizada com a utilização de médias de quatro anos para o período de 1990 a 2009, tendo em vista a necessidade de se ter um mínimo de cinco observações por país para que os testes AR(2) possam ser calculados, e as estimações para os períodos de 1990 a 1999 e de 2000 a 2009 foram feitas com dados anuais.

A equação abaixo descreve o modelo geral de inflação estimado:

$$
\begin{aligned}
& I_{i t}=\alpha+\beta_{1} \text { INF }_{i t-1}+\beta_{2} \text { DUINT }_{i t}+\beta_{3} \text { DUFLEX }_{i t} \\
& +\beta_{4} \text { M2 }_{i t}+\beta_{5} \text { JREAL }_{i t}+\beta_{6} \text { DTCREF }_{i t}+\beta_{7} \text { DIVID }_{i t} \\
& +\beta_{8} \text { DUPD }_{i t}+\beta_{9} \text { DUMETASINF }_{i t}+\beta_{10} \text { DUCAMBMONET }_{i t} \\
& +\beta_{11} \text { DUSUDEENSTOP }_{i t}+\beta_{12} \text { DUBANCARIA }_{i t} \\
& +\beta_{13} \text { DUDIVIDA }_{i t}+\mu_{i}+v_{i t}
\end{aligned}
$$

nifiquem também pelo menos um aumento de $10 \%$ na taxa de depreciação comparada ao ano anterior. Para a crise bancária, os autores definem que nessa condição os setores financeiros e corporativos de um país experimentam grande número de defaults, e tais instituições enfrentam muita dificuldade no pagamento dos contratos no vencimento. Como resultado, empréstimos com problemas de liquidação aumentam bruscamente, e todo o capital agregado do sistema bancário ou sua maioria é esgotado, sendo que o critério utilizado para definir uma corrida bancária é um declínio percentual mensalmente nos depósitos, excedendo a $5 \%$. Já para a crise de dívida, os autores identificam e datam episódios de default de dívida soberana e reestruturação com base nos dados de Beim e Calomiris (2001), World Bank (2002), e Sturzenegger e Zettelmeyer (2006). Essa compilação considera anos de defaults soberanos e de reescalonamento de dívida, sendo identificados 63 episódios desde 1970. Calvo et al. (2008), por sua vez, definem um episódio de reversão brusca de capitais como uma fase que encontra as seguintes condições: i) há pelo menos uma observação em que a queda ano a ano nos fluxos de capital leva a pelo menos dois desvios padrão abaixo de sua média amostral, o que coloca a condição inesperada de uma reversão brusca de capitais; ii) a fase de reversão brusca (sudden stop) termina uma vez que a mudança anual nos fluxos de capital exceda um desvio padrão abaixo de sua média amostral; iii) além disso, a causa da simetria, o início da fase de uma reversão brusca de capitais, é determinada pela primeira vez que a mudança anual nos fluxos de capital cai um desvio padrão abaixo da média.

13 A descrição e fonte das variáveis utilizadas estão apresentadas na Tabela A1 do Apêndice. 
$\mathrm{i}=1,2, \ldots . ., 82 ; \mathrm{t}=1,2, \ldots \ldots, 5 ; \mathrm{em}$ que:

$I N F_{i t}=$ taxa de inflação medida pelo IPC;

$I N F_{i t-1}=$ taxa de inflação medida pelo IPC defasada em um período; $D_{\text {UINT }}$ it = variável dummy, que assume o valor 1 se o país adota regime de câmbio intermediário e valor 0 se não adota esse regime; $;^{14}$

$D_{\text {UFLEX }}$ it = variável dummy, que assume o valor 1 se o país adota regime de câmbio flexível e valor 0 se não adota esse regime;

$M 2_{i t}=$ taxa de crescimento da oferta monetária (M2) em \%;

$J R E A L_{i t}=$ taxa de juros real ex-post em \%;

$D T C R E F_{i t}=$ variação da taxa de câmbio real efetiva; ${ }^{15}$

$D I V I D A_{i t}=$ dívida pública bruta do governo (externa e interna) em $\%$ do PIB;

$D U P D_{i t}=$ variável dummy, que assume o valor 1 se o país é uma economia desenvolvida e valor 0 , caso contrário;

DUMETASINF ${ }_{i t}=$ variável dummy, que assume o valor 1 se o país adotou o regime de metas de inflação e valor 0 , caso contrário; $D U C A M B N O N E T_{i t}=$ variável dummy, que assume o valor 1 se o país vivenciou crise cambial e monetária e valor 0 , caso contrário; DUSUDDENSTOP ${ }_{i t}=$ variável dummy, que assume o valor 1 se o país vivenciou crise de reversão brusca de fluxo de capitais e valor 0 , caso contrário;

$D U B A N C A R I A_{i t}=$ variável dummy, que assume o valor 1 se o país vivenciou crise bancária e valor 0 , caso contrário;

$D U D I V I D A_{i t}=$ variável dummy, que assume o valor 1 se o país vivenciou crise de dívida do governo e valor 0 , caso contrário; $\mu_{i t}=$ efeitos fixos individuais (não observados) constantes no tempo, mas que variam entre os países;

$v_{i t}=$ termo de erro.

14 Os modelos estimados neste artigo utilizam a classificação de regime cambial coarse de Reinhart e Rogoff (2004), que tem seis categorias; porém, essas são consolidadas no presente trabalho em apenas três categorias: regimes fixos (categoria 1), intermediários (categorias 2 e 3) e flexíveis (categorias 4, 5 e 6). No entanto, são utilizados os dados da base de classificação atualizada por Ilzetzki, Reinhart e Rogoff (2010).

$15 \mathrm{Na}$ presente análise, contrariamente ao padrão adotado no Brasil (R \$US\$), variações positivas da taxa de câmbio significam apreciação, ao passo que variações negativas representam depreciação. 
Inicialmente, vale destacar que o objetivo na análise empírica para os modelos de inflação se refere a estudar sua evolução no período a partir dos anos 1990, em especial, por ter ocorrido forte movimento na adoção do regime monetário de metas no mundo e em vista também da falta de consenso empírico quanto aos impactos macroeconômicos do referido regime, em particular, sobre a inflação.

Quanto aos testes para o período completo de 1990 a 2009 sistematizados na Tabela 1, os resultados do modelo 2 estimado por System GMM mostram que os regimes flexíveis são estatisticamente significativos e estão associados a uma inflação mais baixa em comparação aos países de regimes fixos, o que se observa também para os regimes intermediários. Uma possível explicação para esse resultado é que os benefícios de médio e longo prazo de se adotar regimes cambiais flexíveis podem estar associados a menores taxas de inflação no período específico, visto que esses regimes tendem a ser mais duradouros, dado que os regimes fixos podem resultar em colapso cambial em decorrência de problemas de apreciação da taxa de câmbio real e de balanço de pagamentos, além de crises monetárias e cambiais.

Tabela 1 Estimação dos modelos de inflação - System GMM (1990 a 2009)

\begin{tabular}{lrrrrr}
\hline Modelos & Modelo 1 & Modelo 2 & Modelo 3 & Modelo 4 \\
\hline \multirow{2}{*}{ INFL (t-1) } & ${ }^{* * *} 0,262$ & $-0,006$ & $-0,001$ & 0,002 \\
& $(0,06)$ & $(0,01)$ & $(0,01)$ & $(0,01)$ \\
\hline \multirow{2}{*}{ DUINT } & 42,703 & $*-16,173$ & - & - \\
& $(235,08)$ & $(9,20)$ & - & - \\
\hline \multirow{2}{*}{ DUFLEX } & 83,265 & $* *-53,083$ & - & - \\
& $(181,25)$ & $(21,53)$ & - & $*{ }^{* *} 1,810$ \\
M2 & & $* * 1,792$ & $* * * 1,741$ & $(0,14)$ \\
\hline \multirow{2}{*}{ JREAL } & & $(0,13)$ & $(0,15)$ & $-0,088$ \\
& & 0,109 & 0,042 & $(0,16)$ \\
\hline \multirow{2}{*}{ DTCREF } & & $(0,23)$ & $(0,26)$ & $* *-0,435$ \\
& & $* *-0,266$ & $*-0,276$ & $(0,15)$ \\
\hline \multirow{2}{*}{ DIVIDA } & & $(0,13)$ & $(0,16)$ & 0,036 \\
& & $* 0,173$ & 0,005 & $(0,06)$ \\
\hline \multirow{2}{*}{ DUPD } & & $(0,10)$ & $(0,05)$ & 1,008 \\
& & & 4,802 & $(5,24)$ \\
\hline \multirow{2}{*}{ DUMETASINF } & & & $(5,08)$ & $(5,58)$ \\
\hline
\end{tabular}




\begin{tabular}{l|r|r|r|r}
\hline Modelos & Modelo 1 & Modelo 2 & Modelo 3 & \begin{tabular}{r} 
Modelo 4 \\
\hline DUCAMBMONET \\
\end{tabular} \\
\hline & & & $\begin{array}{r}* * *-17,748 \\
(5,88)\end{array}$ \\
\hline DUSUDDENSTOP & & & $\begin{array}{r}0,226 \\
(11,58)\end{array}$ \\
\hline DUBANCARIA & & & $-18,536$ \\
\hline DUDIVIDA & & & $(16,70)$ \\
\hline AR(2) & & & $* 44,059$ \\
\hline Hansen & & & & $(26,48)$ \\
\hline Hansen Difference & 0,394 & 0,997 & 0,820 & 0,389 \\
\hline Número de países & 0,968 & 0,244 & 0,347 & 0,831 \\
\hline Número de instrumentos & 0,930 & 0,645 & 0,624 & 0,912 \\
\hline
\end{tabular}

Fonte: Elaboração dos autores.

Notas: 1) Erros padrão robustos.

2) Os símbolos *, ${ }^{* *} e^{* * *}$ representam coeficientes significantes a $10 \%, 5 \%$ e $1 \%$, respectivamente.

3) Todos os modelos System GMM utilizam dummies temporais.

4) Todos os modelos utilizam procedimento Two-Step.

Quanto ao impacto da inflação passada sobre a inflação corrente, o coeficiente estimado foi positivo e significativo (magnitude de 0,262 ) apenas no modelo 1 da estimação por System GMM.

A variável $\mathrm{M} 2$ se mostrou estatisticamente significativa nos diversos modelos System GMM (coeficientes variando de 1,741 a 1,810), enquanto que dívida do governo (DIVIDA) se mostrou significativa apenas no modelo 2 por System GMM (coeficiente de 0,173), e os sinais positivos dos coeficientes estimados revelam que maior (menor) taxa de crescimento monetário está associada a maior (menor) inflação, o mesmo ocorrendo para a dívida/PIB e sua relação com a taxa de inflação.

Já a variação da taxa de câmbio real efetiva (DTCREF) se mostrou estatisticamente significativa em todos os modelos System GMM, com sinal negativo (coeficientes variando de -0,266 a -0,435), indicando que depreciações (apreciações) cambiais estão associadas a maior (menor) inflação no período.

Além disso, a variável dummy de crise de dívida do governo (DUDIVIDA) apresentou coeficiente positivo e estatisticamente significativo, indicando que os países que vivenciaram episódios de crise de dívida também tiveram maiores taxas de inflação. 
A variável dummy de metas de inflação (DUMETASINF), por sua vez, mostrou coeficiente positivo e significativo no modelo 4 do System GMM, sugerindo que países que adotaram o regime tiveram maior inflação no período, enquanto a variável para países que vivenciaram crise cambial e monetária (DUCAMBMONET) sugere uma associação a menores taxas de inflação. ${ }^{16}$

Por outro lado, a variável taxa de juros real (JREAL) não se mostrou estatisticamente significativa para explicar a inflação no período analisado, fato que se verifica também para o caso das variáveis dummies para países desenvolvidos (DUPD), países que vivenciaram crise bancária (DUBANCARIA) e crise de reversão brusca de fluxo de capitais (DUSUDDENSTOP). ${ }^{17}$

\subsection{Resultados empíricos (1990 a 1999)}

Uma vez realizadas as estimações dos modelos de inflação System GMM para o período de 1990 a 2009, e considerando que os resultados dos coeficientes estimados das dummies de regimes cambiais (DUFLEX e DUINT) não apresentaram resultados consistentes com aqueles sugeridos por boa parte da literatura empírica, além de outros resultados também inconsistentes com a literatura, como o caso das dummies para regime de metas de inflação, optou-se por reestimar o modelo de inflação, porém, subdividido em duas décadas. Além dessa motivação empírica fornecida pelos resultados econométricos, há clara percepção de que tais décadas foram bastante distintas quanto ao comportamento inflacionário de boa parte das economias da amostra, em especial, os países emergentes e em desenvolvimento. Um dado representativo desse argumento é que a inflação média, dentre as 82 economias utilizadas na análise econométrica, é reduzida de 77,89\% na década de 1990 para 40,11\% nos anos 2000.

Diferentemente dos resultados dos modelos do período completo de 1990 a 2009 apresentados na Tabela 1, quando se analisam distintamente os modelos em dois períodos, de 1990 a 1999 (Tabela 2) e de 2000 a 2009 (Tabela 3), os testes apontam para novos resultados para as diversas variáveis analisadas.

16 A Tabela A2 do Apêndice apresenta os países que adotaram o regime de metas de inflação dentro da amostra utilizada de 82 países.

$17 \mathrm{Na}$ presente análise, são considerados países em desenvolvimento e emergentes, aqueles com renda per capita anual abaixo de US\$ 8.000. 
Para o período de 1990 a 1999, um primeiro resultado mostra que os regimes flexíveis (DUFLEX) estão associados a uma inflação mais elevada comparativamente aos regimes fixos, em conformidade com a literatura empírica, embora essa evidência seja estatisticamente significativa apenas em um dos modelos com estimação System GMM (modelo 2), mas com coeficientes estimados positivos em ambos os modelos. Por sua vez, os coeficientes estimados para os regimes intermediários não se mostram estatisticamente significativos, ainda que, em um dos modelos estimados, o coeficiente seja positivo.

Verificando o impacto da inflação passada sobre a inflação corrente, os coeficientes estimados foram positivos (e variam de 0,054 a 0,244 ), indicando a existência de inércia ou persistência inflacionária, sendo que todos os coeficientes estimados foram estatisticamente significativos.

A taxa de crescimento monetário (M2), por sua vez, não se mostrou estatisticamente significativa em explicar o comportamento da inflação, ao passo que a dívida do governo apresentou coeficiente positivo, sendo significativo no modelo 3 , mostrando impacto na inflação no período.

Tabela 2 Estimação dos modelos de inflação - System GMM (1990 a 1999)

\begin{tabular}{lrrrrr}
\hline Modelos & Modelo 1 & Modelo 2 & Modelo 3 & Modelo 4 \\
\hline Proliferação de Instrumentos & Com Collapse & Com Collapse & Com Collapse & Com Collapse \\
\hline \multirow{2}{*}{ INFL (t-1) } & ${ }^{* *} 0,054$ & ${ }^{* *} 0,196$ & $* * * 0,234$ & $* * * 0,244$ \\
& $(0,01)$ & $(0,04)$ & $(0,04)$ & $(0,07)$ \\
\hline \multirow{2}{*}{ DUINT } & $-11,571$ & 12,285 & - & - \\
& $(30,00)$ & $(12,23)$ & - & - \\
\hline \multirow{2}{*}{ DUFLEX } & 225,212 & $* * 27,299$ & - & - \\
& $(161,98)$ & $(13,27)$ & - & - \\
M2 & & $-0,050$ & $-0,049$ & $-0,053$ \\
& & $(0,23)$ & $(0,27)$ & $(0,27)$ \\
\hline \multirow{2}{*}{ JREAL } & & $* *-0,423$ & $* * *-0,735$ & $* *-0,770$ \\
& & $(0,16)$ & $(0,24)$ & $(0,38)$ \\
DTCREF & & $* 0,151$ & 0,079 & 0,100 \\
& & $(0,08)$ & $(0,14)$ & $(0,24)$ \\
\hline \multirow{2}{*}{ DIVIDA } & & 0,003 & $* * 0,179$ & 0,150 \\
& & $(0,10)$ & $(0,08)$ & $(0,11)$ \\
\hline \multirow{2}{*}{ DUPD } & & & $* *-40,894$ & $*-36,650$ \\
& & & $(18,39)$ & $(21,13)$ \\
\hline \multirow{2}{*}{ DUMETASINF } & & & $(8,11)$ & $(18,40)$ \\
\hline
\end{tabular}




\begin{tabular}{l|r|r|r|r}
\hline Modelos & Modelo 1 & Modelo 2 & Modelo 3 & Modelo 4 \\
\hline DUCAMBMONET & & & 5,874 \\
\hline DUSUDDENSTOP & & & $(14,58)$ \\
\hline DUBANCARIA & & & 0,091 \\
& & & $(3,79)$ \\
\hline DUDIVIDA & & & 9,086 \\
& & & & $(5,98)$ \\
\hline AR(2) & & & $-5,567$ \\
\hline Hansen & & & 0,330 & $(32,39)$ \\
\hline Hansen Difference & 0,321 & 0,383 & 0,348 \\
\hline Número de países & 0,008 & 0,932 & 0,748 & 0,941 \\
\hline Número de instrumentos & 0,659 & 0,828 & 1,000 & 1,000 \\
\hline
\end{tabular}

Fonte: Elaboração dos autores.

Notas: 1) Erros padrão robustos.

2) Os símbolos ${ }^{*},{ }^{* *} e^{* * *}$ representam coeficientes significantes a 10\%, 5\% e 1\%, respectivamente.

3) Todos os modelos System GMM utilizam dummies temporais.

4) Todos os modelos utilizam procedimento Two-Step.

A variação da taxa de câmbio real efetiva, analisada apenas no período da década de 1990, não confirma os resultados anteriores, de que as depreciações (apreciações) estão associadas a maior (menor) inflação, tendo significância estatística em apenas um dos modelos System GMM (modelo 2) e coeficiente com sinal positivo, contrário ao anteriormente encontrado.

Um resultado interessante é que a variável de taxa de juro real é estatisticamente significativa no novo período analisado com coeficientes estimados negativos (variando de $-0,423$ a $-0,770$ ) em todos os modelos System GMM, revelando que taxas de juros reais mais altas (baixas) estão associadas a taxas de inflação mais baixas (altas).

Além disso, a variável dummy para países desenvolvidos (DUPD) é estatisticamente significativa e com coeficientes estimados negativos (com valores de -40,894 e -36,650), indicando que esse grupo de economias está associado a menores taxas de inflação quando comparado à média das taxas de inflação das economias emergentes e em desenvolvimento.

Um resultado relevante é que a variável dummy de metas de inflação (DUMETASINF) se revela como significativa em um dos modelos estimados, mostrando coeficiente estimado negativo nos dois modelos estimados, evidenciando que os países que adotaram o regime de metas de infla- 
ção estiveram associados a menor inflação comparativamente aos países que não adotaram o regime. Esse resultado confirma o que é esperado para a década de 1990, período caracterizado por elevada inflação no mundo e período em que diversas economias adotaram o regime de metas de inflação como estratégia de política monetária.

As demais dummies de crises, cambial e monetária, reversão brusca de fluxo de capitais, bancária e de dívida não se mostraram estatisticamente significativas em explicar o comportamento da inflação. ${ }^{18}$

\subsection{Resultados empíricos (2000 a 2009)}

Já a análise de 2000 a 2009 mostra que nesse período somente o modelo 1, o mais parcimonioso nas estimações por System GMM, aponta a ocorrência de uma relação contrária e estatisticamente significativa, indicando que os países com regime flexível tiveram na média inflação menor do que a dos países que adotaram regimes de câmbio rígido/fixo. Os demais resultados quanto às dummies de regimes cambiais não se mostraram estatisticamente significativos.

Quanto às estimações dos coeficientes da inflação defasada, todos foram positivos e significativos nas estimações System GMM, indicando relação de inércia inflacionária. A magnitude dos coeficientes varia de 0,285 a 0,467 nos anos 2000, porém, os modelos mais completos (modelos 3 e 4) mostram que a magnitude dos coeficientes $(0,298$ e 0,285 , respectivamente) não se altera de forma significativa em relação aos anos 1990 (de 0,234 e de 0,244 , respectivamente).

Tabela 3 Estimação dos modelos de inflação - System GMM (2000 a 2009)

\begin{tabular}{lrrrrr}
\hline Modelos & Modelo 1 & Modelo 2 & Modelo 3 & Modelo 4 \\
\hline $\begin{array}{l}\text { Proliferação } \\
\text { de Instrumentos }\end{array}$ & Com Collapse & Com Collapse & Com Collapse & Com Collapse \\
\hline INFL (t-1) & $* * * 0,467$ & $* * * 0,408$ & $* * 0,298$ & $* * * 0,285$ \\
& $(0,01)$ & $(0,05)$ & $(0,08)$ & $(0,06)$ \\
\hline
\end{tabular}

18 O modelo 2 foi reestimado utilizando as interações entre as dummies de crise com as dummies de regimes cambiais e entre a dummy de metas de inflação com as dummies de regimes cambiais. Os resultados apontam que apenas a interação entre a dummy de crise cambial e monetária com a dummy de regimes intermediários apresentou significância estatística (5\%), com coeficiente estimado de $-43,645$, indicando que países que tiveram alguma crise cambial / monetária e que adotaram regime de câmbio intermediário tiveram inflação menor na média. 


\begin{tabular}{|c|c|c|c|c|}
\hline Modelos & Modelo 1 & Modelo 2 & Modelo 3 & Modelo 4 \\
\hline \multirow{2}{*}{ DUINT } & $-3,161$ & $-3,357$ & - & - \\
\hline & $(3,69)$ & $(7,31)$ & - & - \\
\hline \multirow{2}{*}{ DUFLEX } & $* * *-8,105$ & 14,763 & - & - \\
\hline & $(2,86)$ & $(14,01)$ & - & - \\
\hline \multirow{2}{*}{ M2 } & & $-0,029$ & $-0,414$ & $-0,016$ \\
\hline & & $(0,09)$ & $(0,04)$ & $(0,04)$ \\
\hline \multirow{2}{*}{ JREAL } & & $-0,090$ & $-0,131$ & $-0,223$ \\
\hline & & $(0,17)$ & $(0,16)$ & $(0,13)$ \\
\hline \multirow{2}{*}{ DTCREF } & & $-0,190$ & $-0,120$ & $-0,069$ \\
\hline & & $(0,12)$ & $(0,08)$ & $(0,06)$ \\
\hline \multirow{2}{*}{ DIVIDA } & & 0,012 & 0,026 & 0,047 \\
\hline & & $(0,04)$ & $(0,03)$ & $(0,03)$ \\
\hline \multirow{2}{*}{ DUPD } & & & $* *-8,497$ & $*-7,394$ \\
\hline & & & $(4,03)$ & $(3,81)$ \\
\hline \multirow{2}{*}{ DUMETASINF } & & & 5,509 & 4,102 \\
\hline & & & $(6,64)$ & $(6,11)$ \\
\hline \multirow{2}{*}{ DUCAMBMONET } & & & & 6,045 \\
\hline & & & & $(10,33)$ \\
\hline \multirow{2}{*}{ DUBANCARIA } & & & & 1,863 \\
\hline & & & & $(12,67)$ \\
\hline \multirow{2}{*}{ DUDIVIDA } & & & & 24,931 \\
\hline & & & & $(21,43)$ \\
\hline $\operatorname{AR}(2)$ & 0,837 & 0,230 & 0,064 & 0,486 \\
\hline Hansen & 0,055 & 0,459 & 0,598 & 0,575 \\
\hline Hansen Difference & 0,019 & 0,125 & 0,584 & 0,515 \\
\hline Número de países & 82 & 54 & 55 & 55 \\
\hline Número de instrumentos & 28 & 41 & 53 & 53 \\
\hline
\end{tabular}

Fonte: Elaboração dos autores.

Notas: 1) Erros padrão robustos.

2) Os símbolos *, ** $e^{* * *}$ representam coeficientes significantes a 10\%, 5\% e 1\%, respectivamente.

3) Todos os modelos System GMM utilizam dummies temporais.

4) Todos os modelos utilizam procedimento Two-Step.

As variáveis, taxa de crescimento monetário (M2) e dívida do governo, mostram-se como não estatisticamente significativas na explicação do comportamento da inflação no período.

A variação da taxa de câmbio real efetiva, analisada no período da década de 2000, não evidencia os resultados do período completo, uma vez 
que, apesar de apresentar coeficientes negativos em todos os modelos estimados por System GMM, esses não são significativos.

A variável de taxa de juro real efetiva também teve coeficientes estimados negativos e não significativos em todas as estimações System GMM para a década de 2000. Ao se comparar os resultados dos anos 2000 (Tabela 3) com os dos anos 1990 (Tabela 2), percebe-se que a magnitude dos coeficientes estimados é maior para a década de 1990, período em que ocorreram problemas inflacionários mais graves (variando de $-0,423$ a -0,770 na década de 1990 e de -0,090 a -0,223 na década de 2000).

A variável dummy para países desenvolvidos (DUPD) é estatisticamente significativa e com coeficientes estimados negativos, variando de -8,497 a $-7,394$, o que confirma o resultado obtido nos anos 1990, de que tal grupo de economias está associado a menores taxas de inflação.

Além disso, os resultados dos modelos estimados revelam que as variáveis dummies de metas de inflação, de ocorrência de crise cambial e monetária, crise bancária e de crise de dívida de governo não foram estatisticamente significativas para explicar o comportamento da inflação na década de $2000 .{ }^{19}$

Sintetizando, os resultados empíricos dos três períodos avaliados revelam um caráter dúbio ou não consensual na relação entre regime cambial e inflação, indicando ainda a importância de outras variáveis para o comportamento da inflação, como a taxa de crescimento da oferta monetária, a dívida do governo, a variação da taxa de câmbio real efetiva, a taxa de juros real, além da relevância da inflação defasada. Uma evidência restrita ao período de 1990 a 1999 é de que os países que adotaram o regime de metas de inflação estiveram associados a taxas inflacionárias mais baixas.

\section{Considerações finais}

O presente trabalho teve como objetivo investigar os determinantes da inflação, considerando o papel dos regimes cambiais, elementos da política fiscal e monetária, além da investigação do papel das crises financeiras e da adoção ou não do regime de metas de inflação, para uma amostra de 82

19 De forma idêntica ao que foi efetuado para o período de 1990 a 1999, o modelo 2 foi reestimado também para o período de 2000 a 2009 utilizando as interações entre as dummies de crise com as dummies de regimes cambiais e entre a dummy de metas de inflação com as dummies de regimes cambiais. Os resultados, porém, apontam que, para os anos 2000, não houve significância estatística em nenhuma das interações descritas. 
economias no período de 1990 a 2009, utilizando a análise de dados em painel com a metodologia System GMM.

As evidências encontradas revelaram um caráter dúbio ou não consensual na relação entre regime cambial e inflação, além de indicar outras variáveis importantes para o comportamento da inflação. Uma contribuição importante do presente artigo é que os modelos estimados analisam não apenas o papel dos regimes cambiais para a inflação, mas também investigam o papel das crises financeiras e da adoção dos regimes de metas de inflação, o que, em geral, não é feito de forma conjunta em outros trabalhos. Estudos futuros podem incluir dados mais recentes relativos à crise financeira internacional iniciada em 2008 para mensurar o impacto dessa crise sobre o comportamento da inflação no mundo.

Observa-se que existem alguns resultados conflitantes com os encontrados pela literatura empírica (inflação e regimes cambiais; contudo, tais resultados envolvem amostra distinta de países e períodos, além de diferentes especificações (variáveis) dos modelos estimados. De outro lado, alguns resultados são compatíveis com as evidências anteriores. Um exemplo disso é o fato de que, nos anos 1990 (Tabela 2), quando predominam problemas inflacionários mais significativos e adoção de câmbio rígido por várias economias, especialmente emergentes e em desenvolvimento, os regimes flexíveis estão associados a inflação mais alta, ou seja, foi importante a adoção de alguma forma de rigidez cambial (âncora) no combate à inflação, o que não acontece nos anos 2000 (Tabela 3), em que o regime cambial não tem significância estatística para o entendimento da inflação. Talvez isso se deva ao fato de que, nos anos 2000, várias das economias tinham adotado alguma forma de controle inflacionário atrelado a uma regra monetária em vez de ancoragem cambial, na qual o papel da taxa de câmbio (variação) estaria explicitada como um dos determinantes dessa regra monetária, o que não foi objeto de investigação deste trabalho de forma explícita, ainda que seja incluída a variação da taxa de câmbio real efetiva (DTCREF) no modelo.

\section{Referências}

ARELLANO, M.; BOND, S. Some tests of specification for Panel Data: Monte Carlo evidence and an application to employment equations. Review of Economic Studies, v.58, n. 2, 1991. 
ARELLANO, M.; BOVER, O. Another look at the instrumental-variable estimation of error-components models. Journal of Econometrics, v.68, n. 1, p. 29-51, 1995.

ALFARO, L. Inflation, openness, and exchange rate regimes, the quest for short-term commitment. Journal of Development Economics, v.77, p. 229-249, 2005.

BARRO, R. J.; GORDON, D. B. A positive Theory of Monetary Policy in a natural rate model, Journal of Political Economy, v.91, n. 4, p. 589-610, 1983.

BEIM, D.; CALOMIRIS, C. Emerging Financial Markets. McGraw-Hill/Irwin Publishers, 2001.

BIONDI, R. L.; TONETO JÚNIOR, R. Regime de metas inflacionárias: Os impactos sobre o desempenho econômico dos países. Estudos Econômicos, v. 38, n. 4, p. 873-903, out-dez 2008.

BLEANEY, M.; FRANCISCO, M. Exchange rate regimes, inflation and growth in developing countries - An assesment. Journal of Macroeconomics, v. 7, n. 1, article 18, 2007.

BLUNDELL, R.; BOND, S. Initial conditions and moment restrictions in Dynamic Panel Data Models. Journal of Econometrics, v.87, n. 1, p.115-143, 1998.

CALVO, G. A.; REINHART, C. M. Fear of floating. Quarterly Journal of Economics 107, 2002.

CALVO, G. A. On the time consistency of optimal policy in a monetary economy. Econometrica, v.46, n. 6, p. 1411-1428, 1978.

CALVO, G. A.; VÉGH, C. Inflation stabilization in chronic inflation countries. In: TAYLOR, J.; WOODFORD, M. (Eds.). Handbook of Macroeconomics, North Holland, 1999.

CALVO, G. A.; IZQUIERDO, A.; MEJÍA, L-F. Systemic sudden stops: The relevance of balance-sheet effects and financial integration. National Bureau of Economic Research, 14026, 2008.

DE GRAUWE, P.; SCHNABL, G. Exchange rate stability, inflation and growth in (South) Eastern and Central Europe. Review of Development Economics, v.12, n. 3, p. 530-549, 2008.

EDWARDS, S.; LEVY-YEYATI, E. Flexible exchange rates as shock absorbers. European Economic Review, v.59, n. 8, p. 2079-2105, 2005.

EDWARDS, S. The relationship between exchange rates and inflation targeting revisited. National Bureau of Economic Research, Working Paper Series No. 12163, 2006.

FISCHER, S. Exchange rate regimes: Is the bipolar view correct? Journal of Economic Perspectives, v. 15, n. 2, p. 3-24, 2001.

FLEMING, M. Domestic financial policies under fixed and floating exchange rates. IMF Staff Papers, v. 9, p. 369-380, 1962.

FRAGA, A.; GOLDFAJN, I.; MINELLA, A. Inflation targeting in emerging market economies. Banco Central do Brasil, Trabalhos para Discussão n. 76, 2003.

FRIEDMAN, M. The role of monetary policy. American Economic Review, 1968.

FMI - FUNDO MONETÁRIO INTERNACIONAL. 2013. Disponível em: <http://www.imf. org.br>. Acesso em: 25 de Outubro de 2013.

GHOSH, A. R.; GULDE, A. M.; OSTRY, J. D.; WOLF, H. C. Does the exchange rate regime matter for inflation and growth? National Bureau of Economic Research, No. 5874, 1997a.

GHOSH, A. R.; GULDE, A. M.; OSTRY, J. D.; WOLF, H. C. Does the nominal exchange rate regime matter? International Monetary Fund, Working Paper 95/121, $1997 \mathrm{~b}$. 
GHOSH, A. R.; GULDE, A. M.; WOLF, H. C. Exchange rate regimes: Choices and consequences, MIT Press, 2002.

HUSAIN, A.; MODY, A.; ROGOFF, K. S. Exchange rate regime durability and performance in developing versus advanced economies. Journal of Monetary Economics, 52, p. 35-64, 2005.

ILZETZKI, E.; REINHART, C. M.; ROGOFF, K. S. Exchange rate arrangements entering the $21^{\text {st }}$ century: Which anchor will hold? 2010. Disponível em: <http://personal.lse.ac.uk/ilzetzki/ data.htm>. Acesso em 25 de Fevereiro de 2014.

KLEIN, M. W.; SHAMBAUGH, J. C. Exchange rate regimes in the Modern Era. MIT, 2010.

KYDLAND, F. E.; PRESCOTT, E. C. Rules rather than discretion: The inconsistency of optimal plans. Journal of Political Economy, 85, n. 3, p. 473-492, 1977.

LAEVEN, L.; VALENCIA, F. Systemic banking crises: A new database. IMF 08/224, 2008.

LEVY-YEYATI, E.; STURZENEGGER, F. Exchange rate regimes and economic performance. IMF Staff Papers, v. 47, Special Issue, p. 62-98, 2001.

MOHANTY, M. S.; KLAU, M. Monetary policy rules in emerging market economies: Issues and evidence. Bank for International Settlements, Working Papers No. 149, 2004.

MUNDELL, R. Capital mobility and stabilization policy under fixed and flexible exchange rates. Canadian Journal of Economics and Political Science, v. 29, p. 475-485, 1963.

MUNDELL, R. A Theory of Optimum Currency Areas, American Economic Review, 51, 1961.

REINHART, C. M.; ROGOFF, K. S. The modern history of exchange rate arrangements: A reinterpretation. Quarterly Journal of Economics, v.119, n. 1, p. 1-48, 2004.

ROGOFF, K. The optimal commitment to an intermediate monetary target. Quarterly Journal of Economics, 100 (Nov.), p. 1169-1189, 1985.

ROODMAN, D. How to do xtabond2: An introduction to difference and System GMM in Stata. Stata Journal, 9, p. 86-136, 2009a.

ROODMAN, D. A note on the theme of too many instruments. Oxford Bulletin, 71, $2009 \mathrm{~b}$.

STONE, M.; ROGER, S.; SHIMIZU, S.; NORDSTROM, A.; KISINBAY, T.; RESTREPO, J. The role of the exchange rate in inflation-targeting emerging economies. IMF Paper 267, 2009.

STOTSKY, J. G.; GHAZANCHYAN, M.; ADEDEJI, O.; MAEHLE, N. The relationship between the foreign exchange regime and macroeconomic performance in Eastern Africa. International Monetary Fund, Working Paper 12/148, 2012.

STURZENEGGER, F.; ZETTELMEYER, J. Debt defaults and lessons from a decade of crises. Table 1 in chapter 1. Cambridge: MIT Press, 2006.

TAYLOR, J. B. The role of the exchange rate in monetary-policy rules. The American Economic Review, v. 91, n. 2, p. 263-267, May 2001.

VEGH, C. Stopping high inflation. International Monetary Fund Staff Papers, 39, n. 3, 1992.

WORLD BANK. Global development finance, appendix on commercial debt restructuring. Washington, D. C: World Bank, 2002.

WDI - World Development Indicators. The World Bank. Disponível em: <http://www.worldbank.org>. Acesso em 20 de Março de 2014. 


\section{Sobre os autores}

Carlos de Almeida Cardoso - carlosdealmeidacardoso@hotmail.com

Caixa Econômica Federal, Brasília, DF.

Flavio Vilela Vieira - flaviovieira@ufu.br

Instituto de Economia, Universidade Federal de Uberlândia, Uberlândia, MG. Pesquisador do CNPq.

\section{Sobre 0 artigo}

Recebido em 23 de maio de 2014. Aprovado em 4 de agosto de 2015. 


\section{Apêndice}

Tabela A1 Lista de variáveis - definições e fontes de dados

\begin{tabular}{|c|c|c|}
\hline Variáveis & Definição & Fonte de Dados \\
\hline INF & Taxa de inflação medida pelo IPC (em \%) & WDI \\
\hline DUINT & $\begin{array}{l}\text { Variável dummy para países que adotaram regime de } \\
\text { câmbio intermediário }\end{array}$ & IRR2010 \\
\hline DUFLEX & $\begin{array}{l}\text { Variável dummy para países que adotaram regime de } \\
\text { câmbio flexível }\end{array}$ & IRR2010 \\
\hline DUFIXO & $\begin{array}{l}\text { Variável dummy para países que adotaram regime de } \\
\text { câmbio fixo }\end{array}$ & IRR2010 \\
\hline M2 & $\begin{array}{l}\text { Taxa de crescimento da oferta monetária medida pela } \\
\text { variação no conceito dos meios de pagamentos (M2) } \\
\text { (em \%) }\end{array}$ & WDI \\
\hline JREAL & Taxa de juros real ex-post (em \%) & WDI \\
\hline DTCREF & $\begin{array}{l}\text { Variação da taxa de câmbio real efetiva entre te t-1 } \\
(\mathrm{em} \%)\end{array}$ & WDI \\
\hline DIVIDA & $\begin{array}{l}\text { Dívida pública bruta do governo (externa e interna) } \\
\text { (\% PIB) }\end{array}$ & WDI \\
\hline DUPD & $\begin{array}{l}\text { Variável dummy para países que são economias } \\
\text { desenvolvidas }\end{array}$ & WDI \\
\hline DUMETASINF & $\begin{array}{l}\text { Variável dummy para países que adotaram o regime } \\
\text { de metas de inflação }\end{array}$ & $\begin{array}{r}\text { Fraga, Goldfajn e } \\
\text { Minella (2003) }\end{array}$ \\
\hline DUCAMBMONET & $\begin{array}{l}\text { Variável dummy para países que vivenciaram crise } \\
\text { cambial e monetária }\end{array}$ & $\begin{array}{r}\text { Laeven \& Valencia } \\
\text { (2008) }\end{array}$ \\
\hline DUSUDDENSTOP & $\begin{array}{l}\text { Variável dummy para países que vivenciaram } \\
\text { crise de reversão brusca de fluxo de capitais }\end{array}$ & $\begin{array}{r}\text { Calvo et al. } \\
(2008)\end{array}$ \\
\hline DUBANCARIA & $\begin{array}{l}\text { Variável dummy para países que vivenciaram crise } \\
\text { bancária }\end{array}$ & $\begin{array}{r}\text { Laeven \& Valencia } \\
\text { (2008) }\end{array}$ \\
\hline DUDIVIDA & $\begin{array}{l}\text { Variável dummy para países que vivenciaram crise de } \\
\text { dívida do governo }\end{array}$ & $\begin{array}{r}\text { Laeven \& Valencia } \\
\text { (2008) }\end{array}$ \\
\hline
\end{tabular}

Fonte: Elaboração dos autores.

Obs.: 1) 0 modelo de inflação de 1990 a 2009 utiliza dados com médias de 4 anos, ao passo que, para os períodos de 1990 a 1999 e de 2000 a 2009, os modelos utilizam dados anuais.

2) As abreviaturas das fontes são: WDI = World Bank Data Indicators e IRR2010 = IIzetzki, Reinhart e Rogoff (2010). 
Tabela A2 Lista de países da amostra e suas características

\begin{tabular}{|c|c|c|c|c|}
\hline $\begin{array}{l}\text { Países da } \\
\text { Amostra }\end{array}$ & $\begin{array}{r}\text { Regime Cambial } \\
\text { Predominante }\end{array}$ & $\begin{array}{l}\text { Adoção de Me- } \\
\text { tas de Inflação }\end{array}$ & $\begin{array}{r}\text { Nível de } \\
\text { Desenvolvimento } \\
\text { Predominante }\end{array}$ & $\begin{array}{r}\text { Tipos de Crises } \\
\text { Ocorridas }\end{array}$ \\
\hline África do Sul & Flexível & Sim & PD & _ \\
\hline Alemanha & Fixo & Não & PD & _ \\
\hline Argélia & Intermediário & Não & PED & $\mathrm{CM} / \mathrm{B}$ \\
\hline Argentina & Fixo & Não & PD & $\mathrm{CM} / \mathrm{SS} / \mathrm{B} / \mathrm{D}$ \\
\hline Austrália & Flexível & Sim & PD & - \\
\hline Áustria & Fixo & Não & PD & SS \\
\hline Bangladesh & Intermediário & Não & PED & _ \\
\hline Bélgica & Fixo & Não & PD & _ \\
\hline Bolívia & Intermediário & Não & PED & SS/B \\
\hline Botswana & Intermediário & Não & PED & _ \\
\hline Brasil & Intermediário & Sim & PED & $\mathrm{CM} / \mathrm{SS} / \mathrm{B}$ \\
\hline Burkina Faso & Fixo & Não & PED & $\mathrm{CM} / \mathrm{B}$ \\
\hline Canadá & Intermediário & Sim & PD & - \\
\hline Chile & Intermediário & Sim & PED & SS \\
\hline China & Fixo & Não & PED & B \\
\hline Cingapura & Intermediário & Não & PD & _ \\
\hline Colômbia & Intermediário & Sim & PED & SS/B \\
\hline Congo & Fixo & Não & PED & $\mathrm{CM} / \mathrm{B}$ \\
\hline Coréia do Sul & Intermediário & Sim & PD & $\mathrm{CM} / \mathrm{SS} / \mathrm{B}$ \\
\hline Costa do Marfim & Fixo & Não & PED & CM/D \\
\hline Costa Rica & Intermediário & Não & PED & $\mathrm{CM} / \mathrm{SS} / \mathrm{B}$ \\
\hline Dinamarca & Fixo & Não & PD & - \\
\hline Egito & Fixo & Não & PED & $\mathrm{CM}$ \\
\hline El Salvador & Fixo & Não & PED & SS \\
\hline Equador & Fixo & Não & PED & $\mathrm{CM} / \mathrm{SS} / \mathrm{B} / \mathrm{D}$ \\
\hline Espanha & Fixo & Sim & PD & SS \\
\hline Estados Unidos & Flexível & Não & PD & B \\
\hline Filipinas & Intermediário & Não & PED & $\mathrm{CM} / \mathrm{SS} / \mathrm{B}$ \\
\hline Finlândia & Fixo & Sim & PD & $\mathrm{CM} / \mathrm{B}$ \\
\hline França & Fixo & Não & PD & SS \\
\hline Gâmbia & Intermediário & Não & PED & $\mathrm{CM}$ \\
\hline Gana & Intermediário & Não & PED & $\mathrm{CM}$ \\
\hline Grécia & Fixo & Não & PD & SS \\
\hline
\end{tabular}




\begin{tabular}{|c|c|c|c|c|}
\hline $\begin{array}{l}\text { Países da } \\
\text { Amostra }\end{array}$ & $\begin{array}{r}\text { Regime Cambial } \\
\text { Predominante }\end{array}$ & $\begin{array}{l}\text { Adoção de Me- } \\
\text { tas de Inflação }\end{array}$ & $\begin{array}{r}\text { Nível de } \\
\text { Desenvolvimento } \\
\text { Predominante }\end{array}$ & $\begin{array}{r}\text { Tipos de Crises } \\
\text { Ocorridas }\end{array}$ \\
\hline Guatemala & Intermediário & Não & PED & _ \\
\hline Haiti & Intermediário & Não & PED & $\mathrm{CM} / \mathrm{B}$ \\
\hline Holanda & Fixo & Não & PD & _ \\
\hline Honduras & Intermediário & Não & PED & $\mathrm{CM} / \mathrm{SS}$ \\
\hline Índia & Intermediário & Não & PED & B \\
\hline Indonésia & Intermediário & Não & PED & $\mathrm{CM} / \mathrm{SS} / \mathrm{B} / \mathrm{D}$ \\
\hline Irã & Intermediário & Não & PED & $C M / D$ \\
\hline Irlanda & Fixo & Não & PD & - \\
\hline Islândia & Intermediário & Sim & PD & - \\
\hline Israel & Intermediário & Sim & PD & _ \\
\hline Itália & Fixo & Não & PD & _ \\
\hline Jamaica & Intermediário & Não & PED & $\mathrm{CM} / \mathrm{B}$ \\
\hline Japão & Flexível & Não & PD & $\mathrm{B}$ \\
\hline Jordânia & Fixo & Não & PED & SS \\
\hline Malásia & Intermediário & Não & PED & $\mathrm{CM} / \mathrm{SS} / \mathrm{B}$ \\
\hline Malawi & Intermediário & Não & PED & $\mathrm{CM} / \mathrm{SS}$ \\
\hline Madagascar & Intermediário & Não & PED & $\mathrm{CM}$ \\
\hline Marrocos & Intermediário & Não & PED & - \\
\hline México & Intermediário & Sim & PED & $\mathrm{CM} / \mathrm{SS} / \mathrm{B}$ \\
\hline Nicarágua & Intermediário & Não & PED & $\mathrm{CM} / \mathrm{B}$ \\
\hline Niger & Fixo & Não & PED & $\mathrm{CM}$ \\
\hline Nigéria & Intermediário & Não & PED & $\mathrm{CM} / \mathrm{B}$ \\
\hline Noruega & Intermediário & Sim & PD & $\mathrm{B}$ \\
\hline Nova Zelândia & Intermediário & Sim & PD & _ \\
\hline Panamá & Fixo & Não & PED & _ \\
\hline Papua Nova Guiné & Intermediário & Não & PED & $\mathrm{CM}$ \\
\hline Paquistão & Intermediário & Não & PED & SS \\
\hline Paraguai & Intermediário & Não & PED & $\mathrm{CM} / \mathrm{SS} / \mathrm{B}$ \\
\hline Peru & Intermediário & Sim & PED & SS \\
\hline Portugal & Fixo & Não & PD & SS \\
\hline Quênia & Intermediário & Não & PED & $\mathrm{CM} / \mathrm{B}$ \\
\hline Reino Unido & Intermediário & Sim & PD & B \\
\hline $\begin{array}{l}\text { República Demo- } \\
\text { crática do Congo }\end{array}$ & Flexível & Não & PED & $\mathrm{CM} / \mathrm{B}$ \\
\hline
\end{tabular}




\begin{tabular}{|c|c|c|c|c|}
\hline $\begin{array}{l}\text { Países da } \\
\text { Amostra }\end{array}$ & $\begin{array}{r}\text { Regime Cambial } \\
\text { Predominante }\end{array}$ & $\begin{array}{l}\text { Adoção de Me- } \\
\text { tas de Inflação }\end{array}$ & $\begin{array}{r}\text { Nível de } \\
\text { Desenvolvimento } \\
\text { Predominante }\end{array}$ & $\begin{array}{r}\text { Tipos de Crises } \\
\text { Ocorridas }\end{array}$ \\
\hline $\begin{array}{l}\text { República } \\
\text { Dominicana }\end{array}$ & Intermediário & Não & PED & $\mathrm{CM} / \mathrm{SS} / \mathrm{D}$ \\
\hline Senegal & Fixo & Não & PED & $\mathrm{CM}$ \\
\hline Serra Leoa & Intermediário & Não & PED & $\mathrm{CM} / \mathrm{SS} / \mathrm{B}$ \\
\hline Síria & Intermediário & Não & PED & _ \\
\hline Sri Lanka & Intermediário & Não & PED & SS \\
\hline Suécia & Intermediário & Sim & PD & $\mathrm{CM} / \mathrm{SS} / \mathrm{B}$ \\
\hline Suiça & Intermediário & Sim & PD & _ \\
\hline Tailândia & Intermediário & Sim & PED & $\mathrm{CM} / \mathrm{SS} / \mathrm{B}$ \\
\hline Togo & Fixo & Não & PED & CM/B \\
\hline Trinidad e Tobago & Intermediário & Não & PED & - \\
\hline Tunísia & Intermediário & Não & PED & B \\
\hline Turquia & Flexível & Não & PED & $\mathrm{CM} / \mathrm{SS} / \mathrm{B}$ \\
\hline Uruguai & Intermediário & Não & PED & $\mathrm{CM} / \mathrm{SS} / \mathrm{B} / \mathrm{D}$ \\
\hline Venezuela & Flexível & Não & PED & $\mathrm{CM} / \mathrm{B}$ \\
\hline Zâmbia & Flexível & Não & PED & $\mathrm{CM} / \mathrm{B}$ \\
\hline Zimbabue & Intermediário & Não & PED & $\mathrm{CM} / \mathrm{SS} / \mathrm{B}$ \\
\hline
\end{tabular}

Fonte: Elaboração dos autores.

1) $P D$ significa países desenvolvidos e PED significa países em desenvolvimento e emergentes.

2) CM significa crise cambial e monetária, B refere-se à crise bancária, SS trata-se de crise de reversão brusca dos fluxos de capitais (sudden stops) e D crise da dívida.

Tabela A3 Estatísticas descritivas (1990 a 2009)

\begin{tabular}{lrrrrrr}
\hline Variáveis & Observações & Média & Desvio Padrão & Mínimo & Máximo \\
\hline INF & 1621 & 58,919 & 883,164 & $-7,800$ & 24411,000 \\
\hline M2 & 1443 & 44,847 & 366,838 & $-100,000$ & 7677,830 \\
\hline JREAL & 1323 & 9,597 & 26,396 & $-97616,000$ & 605,440 \\
\hline DTCREF & 1138 & 0,233 & 20,787 & $-150,926$ & 491,090 \\
\hline DIVIDA & 1610 & 69,916 & 68,520 & 4,100 & 2092,920 \\
\hline
\end{tabular}

